\title{
BMJ Open Office work and stretch training (OST) study: effects on the prevalence of musculoskeletal diseases and gender differences: a non-randomised control study
}

Fabian Holzgreve (D) , ${ }^{1}$ Laura Fraeulin (D) ${ }^{1}$ Jasmin Haenel, ${ }^{1}$ Helmut Schmidt, ${ }^{2}$ Andreas Bader, ${ }^{2}$ Markus Frei, ${ }^{3}$ David A Groneberg, ${ }^{1}$ Daniela Ohlendorf (D) , Anke van Mark ${ }^{1}$

To cite: Holzgreve F, Fraeulin L, Haenel J, et al. Office work and stretch training (OST) study: effects on the prevalence of musculoskeletal diseases and gender differences: a non-randomised control study. BMJ Open 2021;11:e044453. doi:10.1136/ bmjopen-2020-044453

- Prepublication history for this paper is available online. To view these files, please visit the journal online (http://dx.doi. org/10.1136/bmjopen-2020044453).

Received 08 September 2020 Revised 22 February 2021 Accepted 24 April 2021

\section{Check for updates}

(c) Author(s) (or their employer(s)) 2021. Re-use permitted under CC BY-NC. No commercial re-use. See rights and permissions. Published by BMJ.

${ }^{1}$ Institute of Occupational Medicine, Social Medicine and Environmental Medicine, Goethe University Frankfurt, Frankfurt am Main, Germany

${ }^{2}$ Corporate Health Promotion, Daimler AG Health and Safety, Stuttgart, Germany

${ }^{3}$ Medical Services Plant Rastatt, Mercedes-Benz AG, Rastatt, Germany

Correspondence to

Fabian Holzgreve;

holzgreve@med.uni-frankfurt.de

\section{ABSTRACT}

Objectives For the prevention of musculoskeletal diseases (MSDs), stretch training can be a measure of the workplace health promotion (WHP) for office workers. This can lead to an increase in mobility and, ultimately, reduce or prevent MSD. The aim of the study was to examine a standardised and individualised stretch training on a device, specifically 'five Business', for the prevalence of MSD.

Design This study is a non-randomised control study. Setting WHP programme with clerical employees of a German car manufacturer.

Participants 252 (110 women; 142 men) subjects (median age of 44 ( $\widetilde{X} 21$ years) finished the study successfully. Inclusion criteria included a full-time employment in the office workplace and subjective health.

Intervention The intervention group completed 22-24 training units of $10 \mathrm{~min}$ each on the 'five-Business' device two times a week for 12 weeks.

Primary and secondary outcome measures Data were collected in the form of a pre-post study Nordic Questionnaire.

Results After the intervention, significantly fewer subjects reported pain in the area of the neck $(-17.79)$, shoulder $(-11.28 \%)$, upper back $(-14.7 \%)$, lower back $(-12.78 \%)$ and feet $(-8.51 \%)$. The gender analysis revealed that women are, in general, more often affected by musculoskeletal complaints than men, especially in the neck (+29.5\%) and feet (+15.03\%). Both sexes had significant reductions of MSD in the most commonly affected regions. Thus, $27.12 \%$ less women reported having neck pain, while $13.14 \%$ less men reported having low back pain.

Conclusions The results suggest that a stretching programme performed for 3 months can reduce musculoskeletal complaints in the most commonly affected areas in office workers. Both men and women benefited from the stretch training to a similar extent, suggesting that this would be a promising measure for therapy and prevention as part of WHP.

\section{Strengths and limitations of this study}

- This study reflects realistic working conditions with the involvement of the works council within the framework of the employees' working hours on a voluntary basis.

- The use of a waiting control group offered every employee the same opportunity to participate in the treatment.

Office workers stretched twice per week for $10 \mathrm{~min}$ each on the 'five-Business' device, which was designed specifically for the application in the office.

- Three sports scientists/physiotherapists accompanied and controlled each training unit, however, such an intensive supervision is not feasible in the everyday work life.

- 1958 office workers were invited to participate in this study, only $313(16 \%)$ took part finally.

\section{INTRODUCTION}

Musculoskeletal diseases (MSDs) are a common health hazard among office workers in industrial nations. ${ }^{1}$ Around $50 \%$ of employees suffer from moderate pain in the back and neck, while $30 \%$ complain of severe pain. ${ }^{2}$ MSD play a decisive role in job absenteeism, ${ }^{3}$ presenteeism, ${ }^{4}$ reduced quality of life $^{3}$ and the incidence of work-related injuries. ${ }^{5}$ In Germany, MSD are the main cause of disability days $(20.9 \%)$, followed by sickness of the respiratory system $(16.0 \%)$ and mental illness $(15.2 \%) .{ }^{6}$ In addition, MSD is the diagnosis which leads to the most downtime costs (17.2 billion $€) .{ }^{7}$ On average, disability due to MSD lasts for 19.7 days, with men being affected more frequently than women. ${ }^{8}$ Occupational risk factors, such as repetitive and static work, poor psychological and social 
conditions are related, in particular, to neck/shoulder pain and low back pain. ${ }^{910}$

Employers have reacted to this by implementing workplace health promotion (WHP) measures to help keep staff healthy. However, in heterogeneously composed staff, WHP are potentially not suited for every individual employee. For example, MSD occur differently in men and women; while women show, generally, a higher prevalence of clinical pain conditions, some specific pain conditions are more common in men. ${ }^{11}$ This is especially the case in the upper extremities area where women appear to suffer more often from musculoskeletal complaints than men. ${ }^{12}$ While neck and shoulder pain are also predominantly found in women, only small gender differences have been reported in the majority of epidemiological pain research on low back pain. ${ }^{10}$ However, literature on the topic is controversially discussed; while some studies have found an increased prevalence in women, ${ }^{13} 14$ others have shown an increase in men ${ }^{15} 16$ and, furthermore, other studies have found no gender-specific differences. ${ }^{17-19}$

One reason for this lack of clarity might be that causes for MSD are multifactorial, for which awareness has risen in recent years. ${ }^{20}$ Often both psychological and postural demands contribute to the development of MSD. Increasing competition and rising productivity requirements lead to increased pressure to meet deadlines and to perform, ${ }^{20}$ while the main working time is spent in offices in a static sitting position in front of a computer. ${ }^{21}$ Both of these demands can lead to unphysiological tension of the musculature and, ultimately, contribute to restrictions in mobility. ${ }^{22}$

Among other methods, such as resistance training, stretch trainings are a promising WHP approach, for which Van Eerd $e t a l^{23}$ found moderate evidence in a systematic review. The primary aim of stretch interventions is to improve mobility and, ultimately, to improve or prevent MSD. This was demonstrated, for example, in an investigation by Shariat $e t a l^{24}$ who compared a stretch intervention to ergonomic adjustments in the office by means of the Cornell Musculoskeletal Disorders Questionnaire. While after 4 months' intervention time, both methods led to improvements in MSD (pain prevalence) in the lower back, shoulders and the neck, after 6 months' intervention time, this improvement was only present in those subjects who had executed the stretching programme.

However, the body of literature regarding stretching intervention for office workers is rather small as the subject is not, as yet, extensively studied. ${ }^{25}$ For example, the programmes investigated so far have scarcely been standardised and have not been individualised. ${ }^{24}{ }^{26}$ The stretching programme 'five Business' ('Five Konzept', Hüfingen, Germany) allows stretching of the trunk on a specially designed device in different degrees of freedom. The training is short and can be done in work clothes. This training programme has the prerequisites to be an effective means of promoting health in the office workplace.
Therefore, the aim of the present intervention control study with the 'five-Business' training is to evaluate a standardised and, at the same time, individualised stretch programme by means of the Nordic Questionnaire. In addition, existing gender differences and gender-specific effects of the intervention should be identified. This study is part of the OST project, which, in addition to MSD, investigates the effects of the 'five-Business' programme on the quality of life and mobility of office workers.

\section{METHODS}

\section{Subjects}

Subjects were recruited among 1958 clerical employees of a German car manufacturer. A total of 252 participants successfully completed the study, while 61 subjects dropped out (intervention group $(\mathrm{IG})=60$; control group $(C G)=1)$. A detailed description of the sample is given in table 1 .

Prior to the study, we randomised in which department of the factory the intervention will take place. The following recruitment strategy consisted of an internal email which was sent by the health department. Via an integrated link, employees could register for participation on a voluntary basis (figure 1); the registration deadline was set at 2 weeks. It was communicated that the training would be carried out during working hours and all participants were asked to pursue (only) their usual leisure activities during the intervention period. In close cooperation with the works council, the training was carried out during working hours. In order to provide all employees with the same opportunity to participate in an intervention during work hours, a waiting control group was included as part of the study design. In addition, a non-randomised allocation procedure based on availability was conducted to enable every employee to participate.

Inclusion criteria included full-time employment in an office workplace, subjective health and freedom from exclusion criteria.

Exclusion criteria covered operations or surgical stiffening of the musculoskeletal system, relevant artificial joint replacement, serious diseases such as ankylosing spondylitis, chronic destructive joint diseases, multiple sclerosis, myodystrophic or neurodegenerative diseases, congenital malposition of the musculoskeletal system or acute diseases such as a herniated disc. In addition, the intake of muscle relaxants or other medications that influence the elasticity of the muscles, as well as pregnancy, were considered contraindicators. Further information can be found in the related methodology article. ${ }^{27}$

All test persons gave a written declaration of consent to participate in the study in advance.

\section{Patient and public involvement}

There were no patients involved in this study.

\section{Intervention program 'five Business'}

The device-supported stretch training 'five Business' (figure 2) is a WHP measure provided by the company 
Table 1 Sociodemographic data of the entire sample

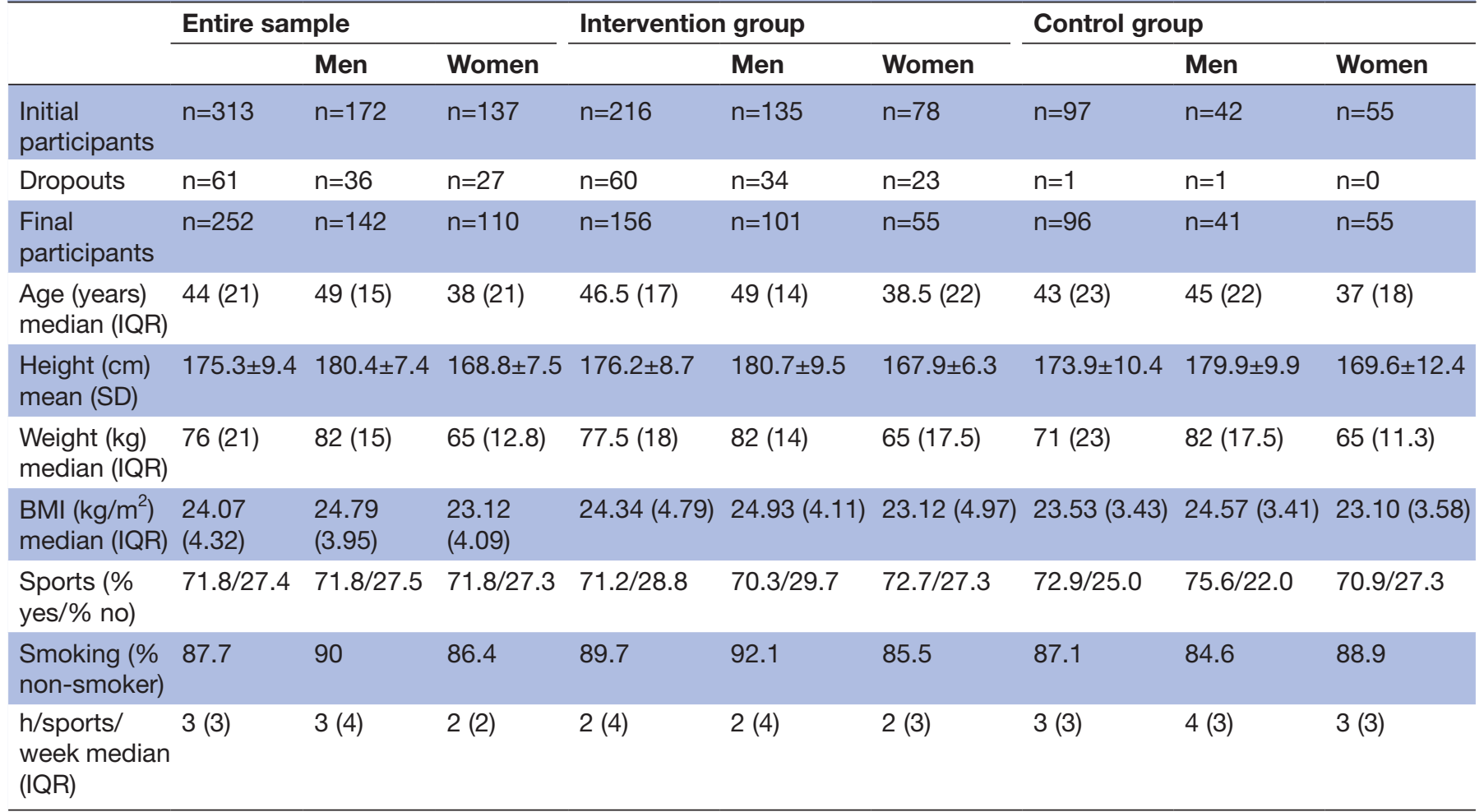

The descriptive statistic is based on the data of the 'final participants'

'Five Konzept'. All exercises can be carried out standing, wearing shoes and in loose working clothes. Subjects held the five stretching positions twice for $20 \mathrm{~s}$ each. Further descriptions can be found in the methodology paper by Holzgreve et $a l^{27}$

\section{Nordic Questionnaire}

The Nordic Questionnaire records musculoskeletal complaints $^{28}$ and has been used internationally in a wide range of professions, ${ }^{29}$ including administrative professions. ${ }^{30}$ The questionnaire asks for information about the person, their work situation and their 7-day, 12-month and lifelong prevalence of musculoskeletal complaints in the neck, shoulder, thoracic and lumbar spine and the joints of the extremities. The duration and frequency of the complaints, resulting impairments at work and participation in leisure activities, as well as physicians' consultations and incapacities to work, are recorded. The questionnaire was digitalised and completed online on site using computers provided for this purpose. The Nordic Questionnaire was provided in German and sociodemographic questions were additionally included.

\section{Measurement protocol}

The data presented here represent a partial evaluation of a larger exploratory research project-the office work and stretch training (OST) study-in which, in addition to MSD, the effects of the 'five-Business' programme on the health-related quality of life and mobility of office workers were investigated. Further details can be found in the related methodology article ${ }^{27}$ and article on effects on the quality of life. ${ }^{31}$ The intervention period covered 12 weeks, with data collection taking place in the week before and after the intervention. One training unit had a duration of about $10 \mathrm{~min}$. During these 12 weeks, the subjects in the IG completed a total of 22-24stretch training sessions, where possible two times a week. Prior to the study, participants were instructed not to start any new treatments during the intervention period. This did not apply to necessary treatments. In order to control for confounders, each participant had to fill out a sports diary on every appointment. If new treatments that had an impact on the musculoskeletal system were started within the intervention period, this resulted in study exclusion. In case of illness or holidays, absences of up to 2 weeks were granted, since this corresponds to the realistic conditions in everyday working life. The test persons were allowed to make up for the missed training sessions through a higher frequency of three training sessions per week. One training session lasted about 10 minutes; each exercise was held twice for $20 \mathrm{~s}$. The correct execution of the exercises was monitored by trained personnel via 1:2 supervisions. Progressive intensity was implemented by the trainers using the variable adjustment function of the device. If participants forgot their training dates, they were contacted and a catch-up date was arranged. In the waiting control group, the measurements were carried out analogous to the IG, but the subjects did not 


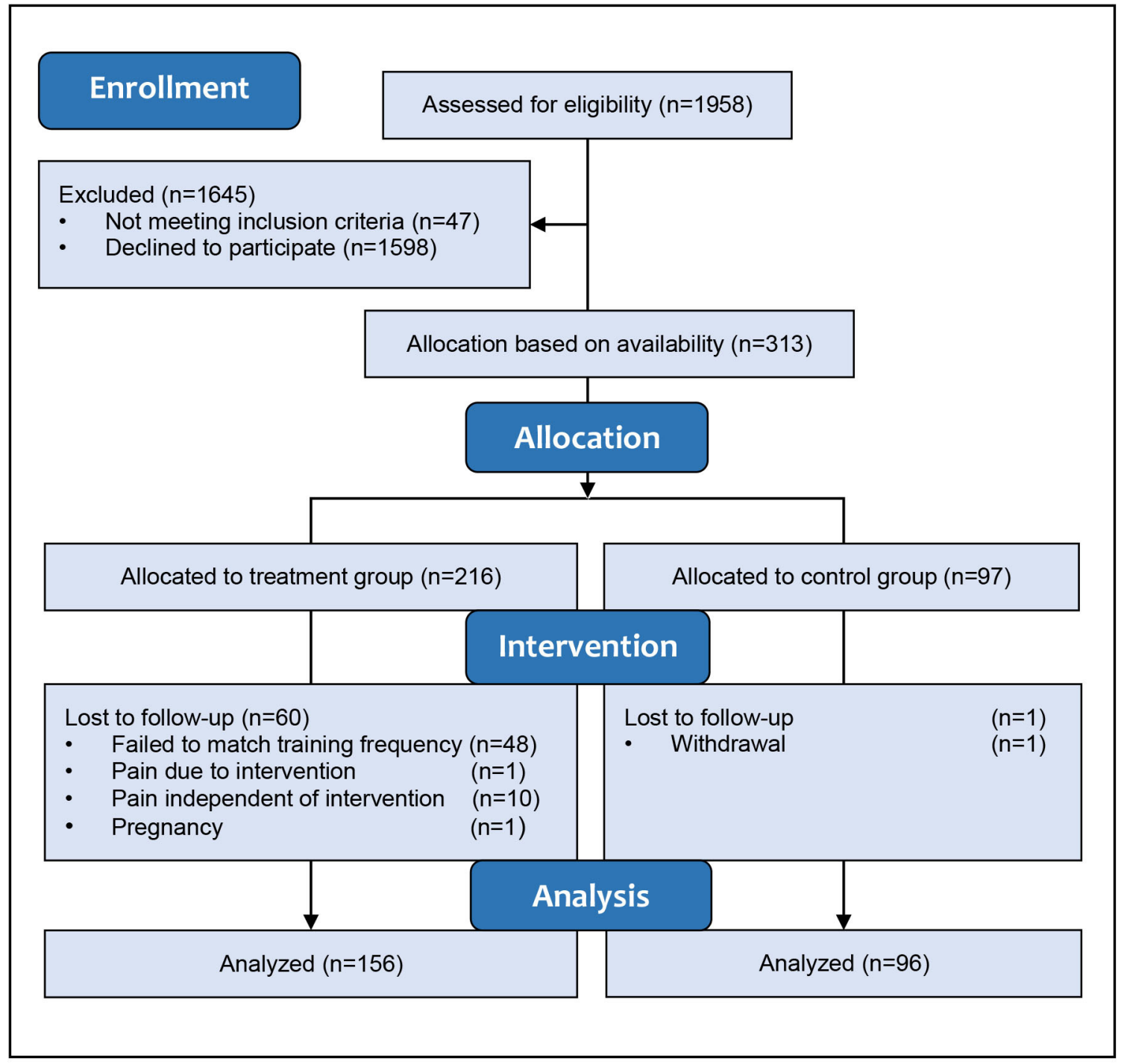

Figure 1 Disposition of study participants. Modified after Holzgreve et al. ${ }^{31}$

train on the 'five-Business' device during the 3-month period. The Nordic Questionnaire was applied at baseline and after 3 months.

\section{Statistical analysis}

The sample size was calculated prior to the study. The calculations have been published in the related methodology article. ${ }^{27}$ Gender differences have not been included in the calculation of the sample size. IBM SPSS Statistics V.26 were used to perform the KolmogoroffSmirnoff-Liliiefors test to asses the normal distribution of the socio-demographic data. In order to obtain descriptive data, either means or medians including SDs or IQRs, respectively, were calculated. The statistics of the Nordic Questionnaire measures were performed with BiAS (V.11.08), including only non-parametric methods, since the response options were dichotomised. For dependent comparisons, the McNemar test was performed. In order to test independent groups, the $\chi^{2}$ test with Yates correction for case numbers $<60$ was used.

\section{RESULTS}

In total, 313 participants (men: $\mathrm{n}=172$; women: $\mathrm{n}=137$ ) aged between 18 and 65 years volunteered to take part in the intervention control study. Of these, 216 were allocated to the IG and 97 to the waiting CG. Two hundred fifty-two subjects (men: $n=142$; women: $n=110$ ) successfully finished the study (table 1). Adverse events due to treatment were almost none. One subject terminated participation due to thoracic spine discomfort. Final participants were 44 years (21) old, $175.3 \mathrm{~cm} \mathrm{(9.4)} \mathrm{tall,}$ weighed $76 \mathrm{~kg}$ (21) and had a body mass index of 24.07 $\mathrm{kg} / \mathrm{m}^{2}$. More than two-thirds of the subjects reported doing sports regularly for about 3 hours/week (table 1).

In the entire sample at baseline, the participants reported the most complaints for the last year in the areas of the neck $(60.66 \%)$, shoulders $(51.02 \%)$ and lower back $(48.37 \%)$. More than a quarter of the participants stated that they had had complaints in the upper back $(25.73 \%)$ and knees $(26.42 \%)$ in the last year (figure 3). 

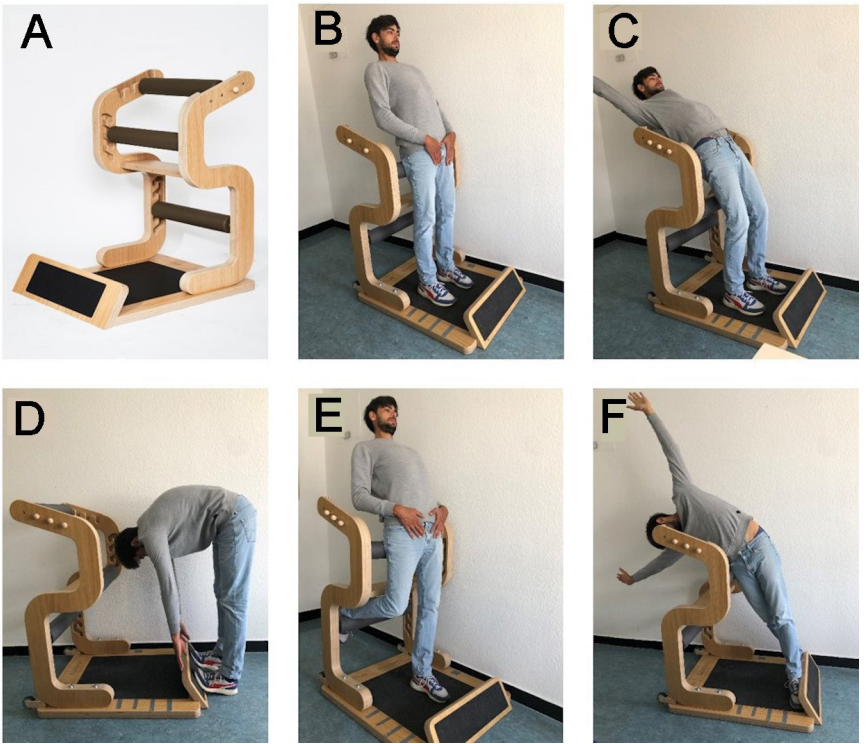

Figure 2 The stretch training on the 'five-Business' device. (A) The device with the dimensions: $116 \mathrm{~cm} \times 82 \mathrm{~cm} \times 128 \mathrm{~cm}$; weight: $60 \mathrm{~kg}$, (B) exercise 'stand', (C) exercise 'chest', (D) exercise 'ischio', (E) exercise 'hip' and (F) exercise 'lateral'.

The calculations of the McNemar test showed that in the IG the proportion of participants with complaints in the neck $(\mathrm{p}<0.001)$, shoulders $(\mathrm{p}<0.02)$, upper back $(\mathrm{p}<0.001)$ and lower back $(\mathrm{p}<0.01)$ had significantly decreased post-intervention (figure 4). In the thighs ( $16.89 \%$ vs $12.16 \%)$, the wrists / hands $(17.57 \%$ vs $13.33 \%)$ and the knees ( $33.55 \%$ vs $26.67 \%$ ), a non-significant trend of a reduction in complaints was observed (figure 4). For the CG, significant differences in pain prevalence could be detected in the neck after 12 weeks compared with the baseline $(\mathrm{p}=0.41)$. Moreover, a non-significant reduction in complaints was evident in the area of the shoulders ( $42.11 \%$ vs $36.46 \%)$, lower back (37.23\% vs $34.74 \%)$ and thighs $(11.83 \%$ vs $8.42 \%)$.

\section{Gender effects}

With the exception of the elbow and lower back, female office workers showed a generally higher 12-month prevalence of musculoskeletal complaints at baseline (figure 5). Both male and female workers had the most complaints in the shoulder/neck area and in the lower back. In almost all areas and in both genders, the prevalence of

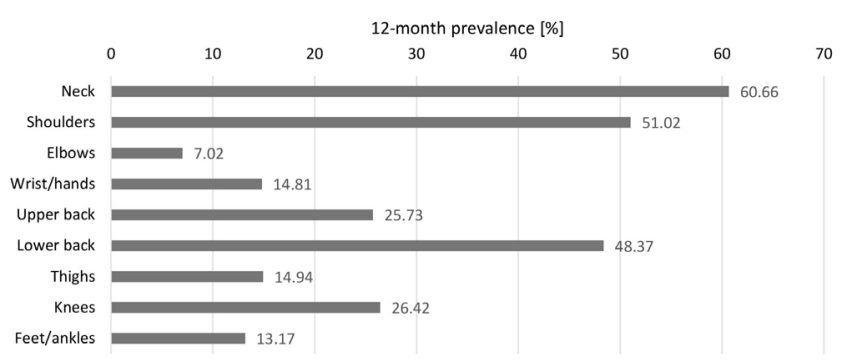

Figure 3 12-Month prevalence of musculoskeletal disease in $(\%)$ of the entire sample at baseline.

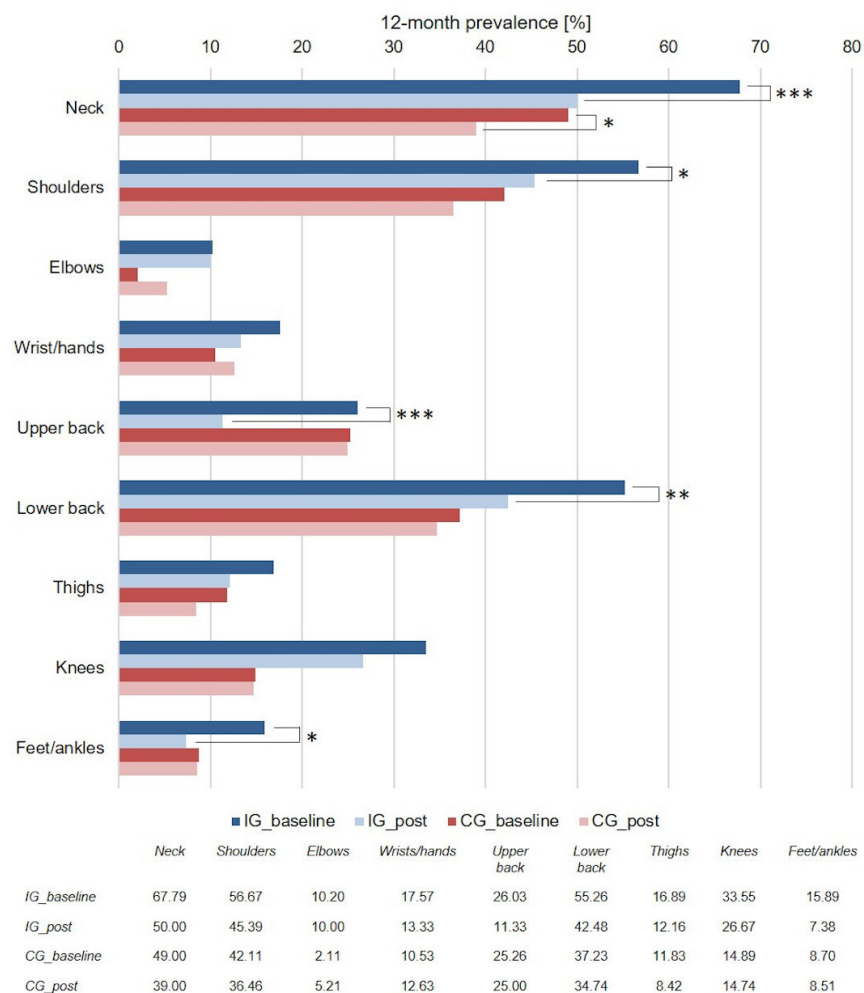

Figure 4 Pre-post comparison of the 12-month prevalence of musculoskeletal disease in (\%) in the IGs and CGs.

Significant differences are marked with asterisks for ${ }^{*} \mathrm{p}<0.05$, ${ }^{\star *} \mathrm{p}<0.01$ and ${ }^{\star \star *} \mathrm{p}<0.001$. CG, control group; IG, intervention group.

musculoskeletal pain decreased after the intervention; this was especially observed in the most heavily affected regions where the employees seemed to benefit particularly from the intervention. It can also be seen that in almost every region, the pain prevalence rates of both sexes were converging. Gender-specific significant differences were found for the neck area between baseline prevalence $(\mathrm{p}<0.001)$ and between baseline and postintervention $(p<0.001)$ in women. Further significant differences were found in the upper back area. Both men $(\mathrm{p}=0.041)$ and women $(\mathrm{p}=0.007)$ had significant reductions of complaints. Moreover, men had significantly $(\mathrm{p}=0.011)$ less back pain after the intervention. In addition, women reported at baseline significantly more often about foot complaints $(\mathrm{p}=0.015)$ than men (figure 5).

\section{DISCUSSION}

The aim of the study was to examine the effectiveness of the 'five-Business' stretch training in reducing MSD concerning the 12-month prevalence among office workers. In addition, gender differences were also identified with regard to the research objective. The results showed a significant reduction in the 12-month prevalence of MSD, following a 3-month stretch training programme, in the area of the neck, shoulders, upper and lower back and the feet (figure 4) in the treatment group. Since these were also the body parts most affected in the 


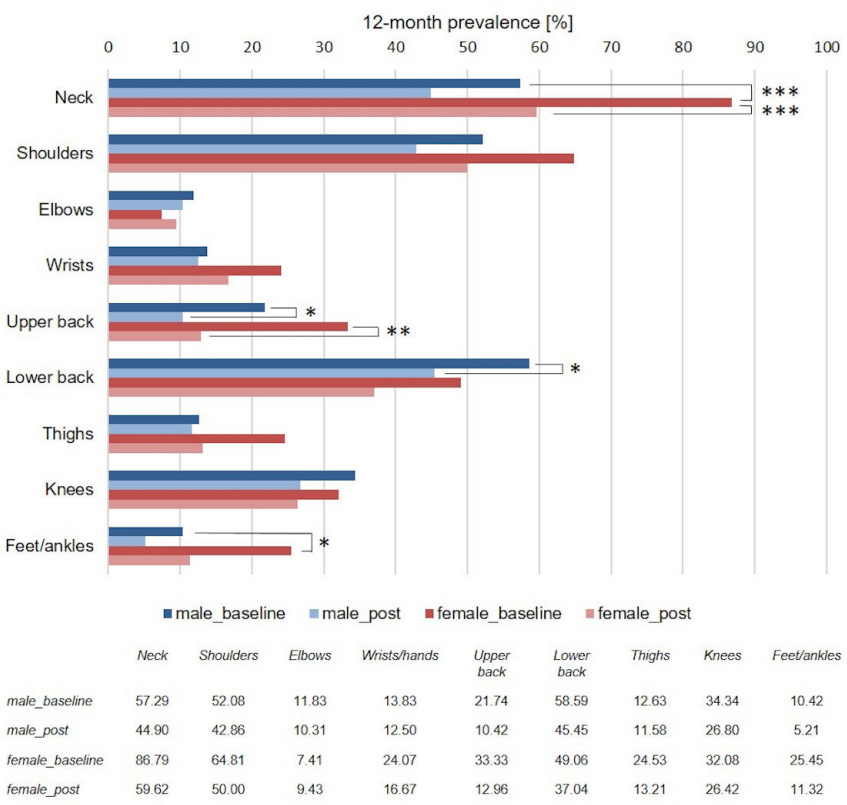

Figure 5 12-month prevalence of musculoskeletal diseases in (\%) at baseline and after intervention, according to gender, for the neck, shoulder, elbow, wrist, upper back, lower back, hip, knee and foot area. Significant differences are marked with asterisks $\left({ }^{*} p<0.0,{ }^{* *} p<0.01\right.$ and $\left.{ }^{* \star *} p<0.001\right)$. For dependent variables, the McNemar test was applied; for independent variables, $\chi^{2}$ with Yates correction for $\mathrm{n}<60$ was used.

baseline results, the reduction in complaints occured in exactly those areas that are exposed to risk factors for MSD from sedentary and static activities ${ }^{910}$ (figures 3 and 4).

The prevalence found is in line with current literature $^{3}$ 32-34 investigating MSD among office workers. Kaliniene $e t a \ell^{33}$ found neck pain in $65.7 \%$, shoulder pain in $50.5 \%$ and low back pain in $56.1 \%$ in a sample of public service computer workers in Lithuania; a similar distribution of complaints was shown in Australian office workers with a prevalence of $76 \%$ (neck), $71 \%$ (shoulders) and $65 \%$ (lower back). ${ }^{32}$ Less complaints, but similar affected areas, have been reported in office workers in Bangladesh $^{3}$ and Iran. ${ }^{34}$

Regarding the stretch trainings as a method to reduce MSD, the few previous studies confirm the current findings. ${ }^{23-25}$ For example, Tunwattanapong et $a l^{26}$ conducted a daily neck and shoulder stretching programme for 4 weeks in office workers with moderate to severe neck or shoulder pain. The treatment group showed a significant decrease in neck and shoulder pain and an improvement in neck function and in the physical dimensions of the SF-36 questionnaire. Similar results have been shown in this study since, here too, especially in the neck and shoulder area, the treatment group showed great improvements (figure 4).

Furthermore, the positive effects on low back pain are also supported by the findings of Lawand $e t a l^{35}$ who showed significant improvements in pain, function and some quality of life aspects in patients with chronic low back pain. In this randomised controlled trial, subjects performed a weekly 60-minute stretching programme, according to the global postural re-education method, over 12 weeks. The intervention period is similar to this study, but with longer stretching sessions. However, in this study, significantly less office workers reported pain in the lower back area $(12.78 \%)$.

The results of this study also showed significant reductions of pain prevalence in the upper back and feet, with reduction trends observed in the wrists, thighs and knees, indicating that this whole body stretching programme is effective in most areas of the body.

In the control group, no difference between baseline and post was observed, except for the neck area $(\mathrm{p}<0.05)$. This unspecific effect may be due to various reasons; for example, the company's appreciation of the employees or the fact that skilled trainers took care of the participants may have led to this.

Gender-specific significant differences were obtained at baseline in the area of the neck (women: $86.62 \%$ vs men: $57.29 \%$ ) and the feet (women: $25.45 \%$ vs men: $10.42 \%$ ) with significant treatment effects observed among men in the upper and lower back and among women in the neck and lower back, respectively (figure 5).

Fundamentally, the results show that women are more likely to report having MSD than men which is in line with the existing evidence ${ }^{11}$; this is especially noticeable in the neck $(+29.5 \%)$, shoulder $(+12.73 \%)$ area and upper back $(+11.59 \%)$ where women seem to be more frequently affected than men (figure 5). These results confirm the contemporary literature that upper extremities MSD and neck/shoulder pain are predominantly found in women. ${ }^{12}$ The exception to this point is the lower back, with $9.53 \%$ more men affected. According to the current state of knowledge, the evidence is unclear concerning genderspecific differences. ${ }^{10}$ In principle, employees seem to benefit particularly in the regions that are most affected. According to this, women benefit particularly in the neck $(p<0.001)$ and men in the lower back $(p<0.05)$. In both groups, a significant reduction in upper back complaints $(\mathrm{p}<0.05$ in men, $\mathrm{p}<0.01$ in women) was also observed. In the area of the shoulders, which was frequently reported, a clear trend can be seen in both sexes $(-9.22 \%$ in men, $-14.81 \%$ in women). It is particularly striking that both the significant regions and the trends after the intervention appeared to be converging. In summary, it can be stated that women in the office workplace generally suffer more frequently from MSD. However, both men and women benefited from the stretching programme.

The study results showed that a device supported standardised and individualised stretch training is suitable as a WHP measure.

When interpreting the presented results, the lack of randomisation has to be taken into account. A randomised allocation to the study groups was not possible due to the organisational structure of the company. However, the aim of this study was to investigate the effects of a WHP 
programme deliberately in the field. In our opinion, this also represents the strength of this study. It was carried out under realistic working conditions with the involvement of the works council within the framework of the employees' working hours on a voluntary basis. Furthermore, such WHP programmes are usually applied in large companies, where cooperation with the works council is essential. Any other approach would have been simply not being possible in this case. In addition, subjects had to arrange training in accordance with business appointments and holidays, randomisation would have threatened the feasibility of this study. This might also explain differences in the group size and gender distribution between the intervention and control group. Furthermore, we were not allowed to randomise selection among participants because of the intervention by the works council and legal department and their concerns about data protection.

In addition to the survey of pain prevalence, an investigation of the days and main causes of sick leave would have been useful. Unfortunately, this was not approved by the works council.

Furthermore, it has to be emphasised that the participants were guided by experienced trainers throughout the 3 months' intervention time. When implementing five business as a WHP programme, an introduction of all employees with regular control appointments is recommended to ensure technically correct execution. Constant monitoring of the training is not necessary. The trainers also arranged new training appointments if subjects missed their session. It is doubtful that participation would have been sufficiently regular without the personal supervision of a trainer. In the framework of the OST project Holzgreve $e t a l^{\beta 1}$ could already show that the stretching intervention has relevant effects on the quality of life. In particular, strong effects were found in the psychological component of the quality of life. With regard to the main causes (MSD and mental illness) of sick leave in Germany, the 'five-Business' programme seems to be a suitable measure for prevention and therapy in the context of health promotion for office workers.

Future studies should aim to implement a follow-up evaluation in order to investigate whether the stretch training can reduce MSD and days of incapacity to work in the long term and evaluate the effects of different intervention periods and training frequencies.

\section{Conclusion}

The results suggest that a stretching programme performed for 3 months can reduce musculoskeletal complaints in the most affected areas in office workers. Both men and women benefited from the stretch training to a similar extent. Concerning the ubiquitous prevalence of MSD in office workers, especially shoulder/neck pain, upper back pain and lower back pain, the stretch programme is proposed to be a promising measure for the therapy and prevention of MSD as part of WHP.
Contributors AvM, HS, MF, AB and DO conceived the original idea. AvM, DO, FH, $\mathrm{LF}$ and $\mathrm{JH}$ conceived and planned the experiments. FH, LF and JH carried out the experiment. DO, AvM, DAG, HS, AB and MF helped supervise the Project. FH wrote the manuscript with support from LF, DAG, AvM and D0. All authors discussed the results and contributed to the final manuscript.

Funding The authors have not declared a specific grant for this research from any funding agency in the public, commercial or not-for-profit sectors.

Competing interests None declared.

Patient consent for publication Obtained.

Ethics approval The study was approved by the Ethics Committee of the Medical Faculty of the Baden-Württemberg Medical Association (F-2017-073). All participants signed an informed consent to participate in advance, so the consent was written. Minors were excluded as participants of this study.

Provenance and peer review Not commissioned; externally peer reviewed. Data availability statement No data are available.

Open access This is an open access article distributed in accordance with the Creative Commons Attribution Non Commercial (CC BY-NC 4.0) license, which permits others to distribute, remix, adapt, build upon this work non-commercially, and license their derivative works on different terms, provided the original work is properly cited, appropriate credit is given, any changes made indicated, and the use is non-commercial. See: http://creativecommons.org/licenses/by-nc/4.0/.

\section{ORCID iDs}

Fabian Holzgreve http://orcid.org/0000-0002-1115-131X

Laura Fraeulin http://orcid.org/0000-0001-5214-5963

Daniela Ohlendorf http://orcid.org/0000-0002-2281-9880

\section{REFERENCES}

1 Celik S, Celik K, Dirimese E, et al. Determination of pain in musculoskeletal system reported by office workers and the pain risk factors. Int J Occup Med Environ Health 2018;31:91-111.

2 Shariat A, Tamrin SBM, Arumugam M, et al. Prevalence rate of musculoskeletal discomforts based on severity level among office workers. Acta Medica Bulgarica 2016;43:54-63.

3 Habib MM, Yesmin SA pilot study of prevalence and distributions of musculoskeletal symptoms (MSS) among paper based office workers in Bangladesh. Work 2015;50:371-8.

4 Aptel M, Aublet-Cuvelier A, Cnockaert JC. Work-related musculoskeletal disorders of the upper limb. Joint Bone Spine 2002;69:546-55.

5 Holder NL, Clark HA, DiBlasio JM, et al. Cause, prevalence, and response to occupational musculoskeletal injuries reported by physical therapists and physical therapist assistants. Phys Ther 1999;79:642-52.

6 Mazda Adli BB, Birner U, Bogert B. BKK Gesundheitsreport 2019. In Knieps HP, ed. Psychische Gesundheit und Arbeit. Berlin, 2019.

7 Brenscheidt S, Siefer A, Hinnenkamp H. Arbeitswelt im Wandel: Zahlen - Daten - Fakten (2019). Ausgabe 2019. Dortmund 2019;86.

8 Marschall Jörg HS, Hans-Dieter N. DAK Gesundheitsreport 2019: Analyse der Arbeitsunfähigkeitsdaten. In: Storm A, ed. Alte und neue Süchte im Betrieb. 244. Hamburg, 2018.

9 Skov T, Borg V, Orhede E. Psychosocial and physical risk factors for musculoskeletal disorders of the neck, shoulders, and lower back in salespeople. Occup Environ Med 1996;53:351-6.

10 Manchikanti L. Epidemiology of low back pain. Pain Physician 2000;3:167-92

11 Berkley KJ. Sex differences in pain. Behav Brain Sci 1997;20:371-80

12 Kim R, Wiest C, Clark K, et al. Identifying risk factors for firstepisode neck pain: a systematic review. Musculoskelet Sci Pract 2018;33:77-83.

13 Bento TPF, Genebra CVDS, Maciel NM, et al. Low back pain and some associated factors: is there any difference between genders? Braz J Phys Ther 2020;24:79-87.

14 Yang L, Grooten WJA, Forsman M. An iPhone application for upper arm posture and movement measurements. Appl Ergon 2017;65:492-500.

15 Aasa U, Barnekow-Bergkvist M, Ängquist KA, et al. Relationships between work-related factors and disorders in the neck-shoulder and low-back region among female and male ambulance personnel. $J$ Occup Health 2005;47:481-9.

16 Hoy D, Brooks P, Blyth F, et al. The epidemiology of low back pain. Best Pract Res Clin Rheumatol 2010;24:769-81. 
17 Olsen TL, Anderson RL, Dearwater SR, et al. The epidemiology of low back pain in an adolescent population. Am J Public Health 1992;82:606-8.

18 Spengler DANM, Bigos SJ, Martin NA, et al. Back injuries in industry: a retrospective study. Spine 1986;11:241-5.

19 Bigos SJ, Battié MC, Spengler DM, et al. A prospective study of work perceptions and psychosocial factors affecting the report of back injury. Spine 1991;16:1-6.

20 Marschall Jörg HS, Hanna S. Sydow Hanna, Nolting HansDieter. In: Storm A, ed. Gesundheitsreport 2017. analyse Der Arbeitsunfähigkeitsdaten. Hamburg: DAK, 2017.

21 Ellegast RP, Kraft K, Groenesteijn L, et al. Comparison of four specific dynamic office chairs with a conventional office chair: impact upon muscle activation, physical activity and posture. Appl Ergon 2012;43:296-307.

22 Page P. Current concepts in muscle stretching for exercise and rehabilitation. Int J Sports Phys Ther 2012;7:109.

23 Van Eerd D, Munhall C, Irvin E, et al. Effectiveness of workplace interventions in the prevention of upper extremity musculoskeletal disorders and symptoms: an update of the evidence. Occup Environ Med 2016;73:62-70.

24 Shariat A, Cleland JA, Danaee M, et al. Effects of stretching exercise training and ergonomic modifications on musculoskeletal discomforts of office workers: a randomized controlled trial. Braz J Phys Ther 2018;22:144-53.

25 Louw S, Makwela S, Manas L, et al. Effectiveness of exercise in office workers with neck pain: a systematic review and metaanalysis. S Afr J Physiother 2017;73:392.

26 Tunwattanapong P, Kongkasuwan R, Kuptniratsaikul V. The effectiveness of a neck and shoulder stretching exercise program among office workers with neck pain: a randomized controlled trial. Clin Rehabil 2016;30:64-72.

27 Holzgreve F, Maltry L, Lampe J, et al. The office work and stretch training (OST) study: an individualized and standardized approach for reducing musculoskeletal disorders in office workers. J Occup Med Toxicol 2018;13:37.

28 Kuorinka I, Jonsson B, Kilbom A, et al. Standardised Nordic questionnaires for the analysis of musculoskeletal symptoms. Appl Ergon 1987;18:233-7.

29 López-Aragón L, López-Liria R, Callejón-Ferre Ángel-Jesús, et al. Applications of the standardized Nordic questionnaire: a review. Sustainability 2017;9:1514.

30 Piranveyseh P, Motamedzade M, Osatuke K, et al. Association between psychosocial, organizational and personal factors and prevalence of musculoskeletal disorders in office workers. Int J Occup Saf Ergon 2016;22:267-73.

31 Holzgreve F, Maltry L, Hänel J, et al. The office work and stretch training (Ost) study: an individualized and standardized approach to improve the quality of life in office workers. Int J Environ Res Public Health 2020;17:4522.

32 Griffiths KL, Mackey MG, Adamson BJ. Behavioral and psychophysiological responses to job demands and association with musculoskeletal symptoms in computer work. J Occup Rehabil 2011;21:482-92.

33 Kaliniene G, Ustinaviciene R, Skemiene L, et al. Associations between neck musculoskeletal complaints and work related factors among public service computer workers in Kaunas. Int J Occup Med Environ Health 2013;26:670-81.

34 Zeİdİ I, Heidarnia AR. Theory-Based education and postural Ergonomic behaviours of computer operators: a randomized controlled trial from Iran. Turkish J Phy Med \& Rehab/Turkiye Fiziksel Tip ve Rehabilitasyon Dergisi 2012;58.

35 Lawand P, Lombardi Júnior I, Jones A, et al. Effect of a muscle stretching program using the global postural reeducation method for patients with chronic low back pain: a randomized controlled trial. Joint Bone Spine 2015;82:272-7. 